DOI: $10.17516 / 1997-1397-2021-14-2-249-257$

УДК 535.247.1

\title{
Photostability of CdTe Quantum Dots and Graphene Quantum Dots under their Continuous Visible and UV Irradiation
}

\author{
Melina A. Goryunova* \\ Aleksei S. Tsipotan ${ }^{\dagger}$ \\ Vitaliy V.Slabko ${ }^{\ddagger}$ \\ Siberian Federal University \\ Krasnoyarsk, Russian Federation
}

Received 10.08.2020, received in revised form 11.01.2021, accepted 20.02.2021

\begin{abstract}
In the last decade, ultraviolet detectors have received significant attention due to their widespread use in civil and military fields. In this work, we have studied the effect of radiation of different ranges (UV and visible) on the spectral properties of CdTe quantum dots and wide-gap graphene QDs. The results obtained can be used to create an integrated UV radiation detector based on new physical principles.
\end{abstract}

Keywords: UV detectors, quantum dots, photostability.

Citation: M.A. Goryunova, A.S. Tsipotan, V.V.Slabko, Photostability of CdTe Quantum Dots and Graphene Quantum Dots under their Continuous Visible and UV Irradiation, J. Sib. Fed. Univ. Math. Phys., 2021, 14(2), 249-257. DOI: 10.17516/1997-1397-2021-14-2-249-257.

\section{Introduction}

Radiation sensors in the UV spectral range have been of great scientific and practical interest for a long time. This is due not only to new scientific data on the effect of UV radiation on human life and health, but also to the awareness of the fact that a number of tasks of an industrial, medical, environmental, security nature can be solved with the help of such sensors [1-4].

At present, the search for new materials for sensors that record the ultraviolet radiation dose is being actively pursued. Thus, the authors of [5] proposed methylammonium lead chloride $(\mathrm{MAPbCl} 3)$ as a material for a UV sensor, on the basis of which a relatively fast detector insensitive in the visible region was obtained. The possibility of detecting ultraviolet radiation was found in a metal-insulator-metal (MIM) structure with carbon-boron nitride [6]. One of the promising materials for UV detection is nanostructured $\mathrm{ZnO}$, in the form of nanodisks [7], nanowires [8] and colloidal quantum dots [9].

The study of the quantum dots (QDs) optical properties is becoming increasingly important in connection with the possible application of semiconductor nanostructures in science and technology, namely in UV sensors. Quantum dots are semiconductor nanoparticles, the electronic properties of which differ significantly from the properties of a bulk material. Quantum dots have

\footnotetext{
* goryunova7816@gmail.com

†acipotan@sfu-kras.ru

‡VSlabko@sfu-kras.ru

(C) Siberian Federal University. All rights reserved
} 
found applications in photovoltaic systems such as light emitting diodes and flat light emitting panels, lasers, solar cells and photovoltaic converters, as biological markers, i.e. wherever variable, wavelength-tunable optical properties are required. Their properties are useful for medical technologies, optoelectronic devices [10-14], etc.

A number of works performed in recent years are devoted to the study of the stability of quantum dots and ways to increase it. The photostability of CdSe / ZnS quantum dots and multilayer graphene was studied in the work [15]. A correlation was established between the quantum yield of QD luminescence and their photoelectric properties in hybrid structures. It is shown that a decrease in the quantum yield of QD luminescence as a result of the adsorption of azo dye molecules 1- (2-pyridylazo) -2-naphthol on the QD surface and a photoinduced increase in the quantum yield of QD luminescence is accompanied by a symbatic change in the photoconductivity of the structures.

The spectral properties of mixtures of colloidal CdS quantum dots with an average diameter of $2.5 \mathrm{~nm}$ and methylene blue molecules dispersed in gelatin are studied. The study by the authors of the works [16] established the manifestations of their hybrid association. An increase in the intensity of methylene blue luminescence in the presence of CdS quantum dots is found. A model of this effect is proposed, based on the transfer of the electronic excitation energy from the luminescence centers of the CdS quantum dot to methylene blue molecules.

The paper proposes a [17] technique for the successful replacement of the organic shell of colloidal QDs of cadmium selenide of various sizes. It was found that the spectral parameters of QD samples depend on the type of organic shell. It is shown that the morphology of structures does not depend on the size of QDs, but is determined by the chemical composition of the organic shell. A spectral analysis of the luminescence of QD-based superstructures showed that the position and intensity of the luminescence band strongly depends on the quality of the QD surface passivation. Previously, the photostability of CdTe colloidal quantum dots was considered in the work [18]. These objects were sensitive to UV radiation, however, their physical properties change significantly, which probably will not allow their use as a material for a UV radiation detector.

The aim of this work is to study the comparative characteristics of the photostability of colloidal CdTe quantum dots and wide-gap graphene quantum dots when they are irradiated with continuous radiation in the visible and UV ranges.

\section{Materials}

We studied water-soluble CdTe quantum dots stabilized with thioglycolic acid with a fluorescence maximum at $550 \mathrm{~nm}$ (PlasmaChem) and graphene colloidal quantum dots (CQD) quantum dots (Sigma Aldrich). The molar concentration of CdTe quantum dots in the solution was $C=3 \cdot 10^{-6} M$, the concentration of graphene dots was $C=1 \cdot 10^{-5} M$ [19]. The structure and local elemental composition of the samples were examined on a JEM-2100 (JEOL), high-resolution transmission electron microscope equipped with an Oxford Inca x-sight energy dispersive spectrometer at an accelerating voltage of $200 \mathrm{kV}$ (Fig. 1).

\section{Experimental setup}

Solutions for studying the photostability of quantum dots were placed in quartz fluorimetric cells $10 \times 10 \mathrm{~mm}$ in size. A DRSh-250-3M lamp operating in a glow mode was used as a light 


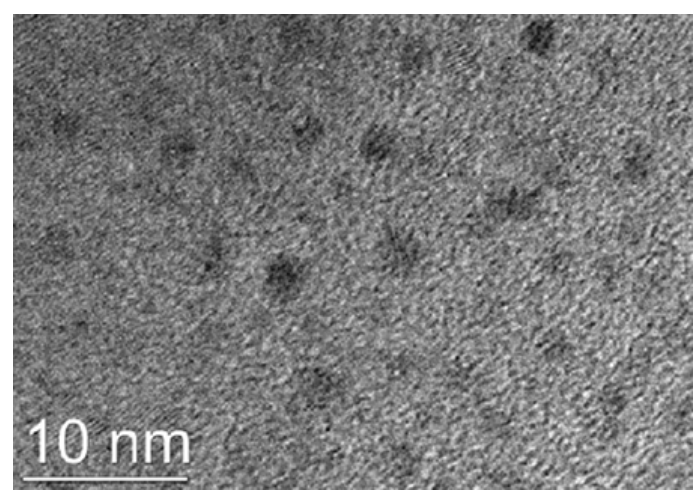

a)

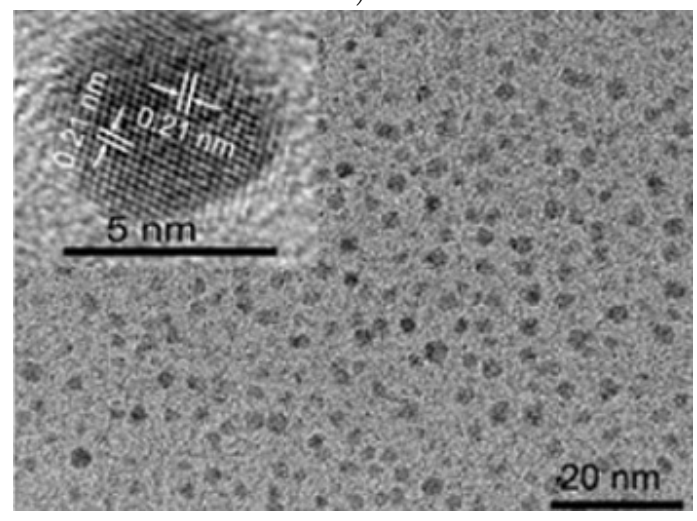

c)

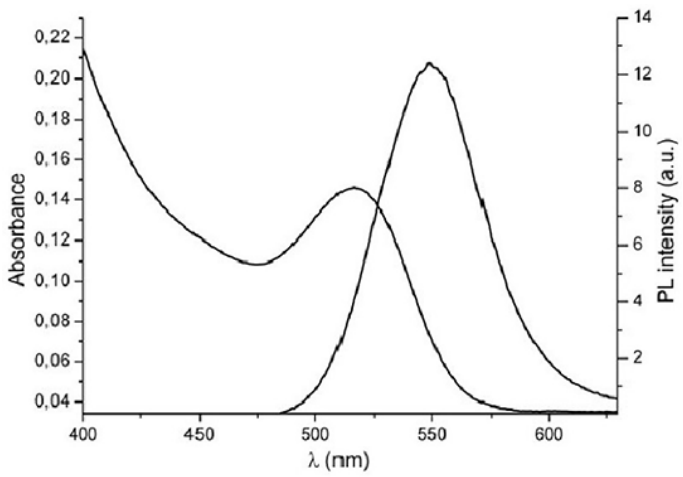

b)

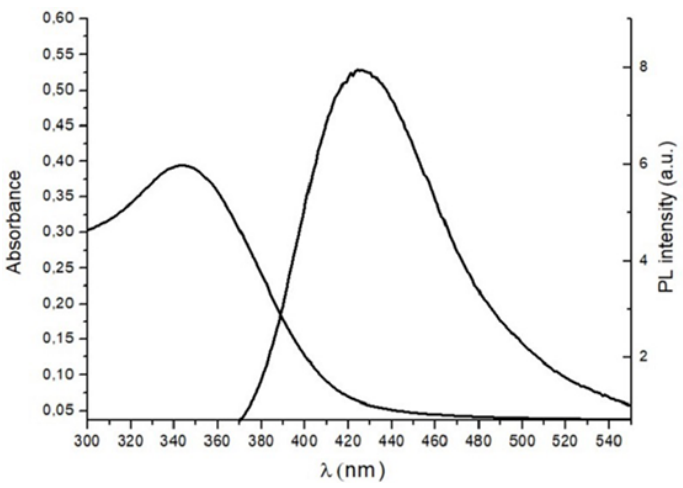

d)

Fig. 1. Physical properties of nanoparticles: electronic photographs of HR TEM CdTe (a), optical properties: absorption and photoluminescence spectra (b) and HR TEM CQD (c) and (d), respectively

source for irradiating the cuvettes. The emission spectrum of the DRSh-250-3M lamp is shown in Fig. 2a. It is a series of bright lines lying in the range from 275 to $600 \mathrm{~nm}$. The selection of ultraviolet and visible ranges was carried out using an appropriate set of light filters, respectively (Fig. 2b and Fig. 2c).

The power was measured using an IMO-2N average power and laser radiation energy meter, and was equal to $P=0,067 \mathrm{~W}$. The same intensity in all experiments equal to $I=379,3 \mathrm{~W} / \mathrm{cm}^{2}$.

The absorption spectra of the solutions were investigated using a Lambda 35 spectrophotometer (PerkinElmer), and fluorescence spectra using a Fluorolog 3 fluorometer (Horiba Jobin Yvon) at room temperature.

\section{Experimental results}

Irradiation with UV and visible ranges of the studied quantum dots was carried out for 60 minutes for each of the samples. The luminescence and absorption spectra were recorded before the beginning of irradiation, during the course with an interval of $10 \mathrm{~min}$, and after irradiation. The evolution of the absorption and luminescence spectra is shown in Figs. 3 and 4.

As can be seen from the figures, the effect of ultraviolet radiation on CdTe quantum dots 


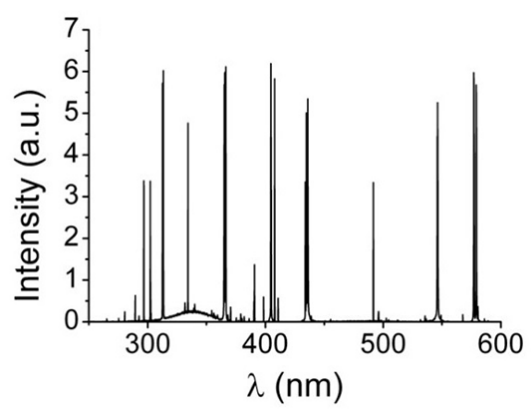

a)

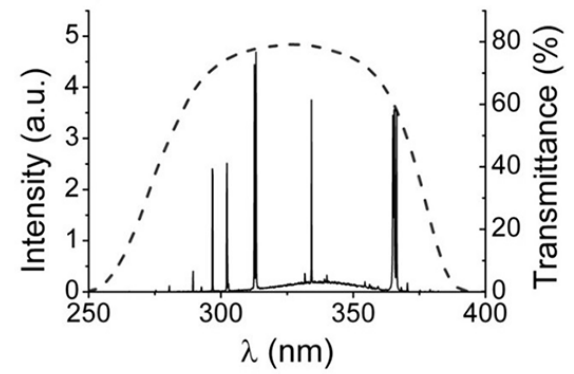

b)

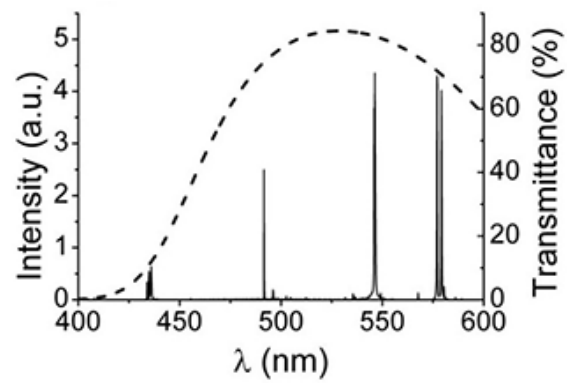

c)

Fig. 2. The dependence of the radiation intensity on the wavelength for the DRSh-250-3M lamp and the spectral ranges of irradiation, taking into account the transmission of light filters

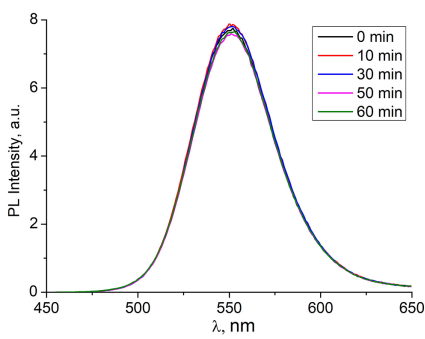

a)

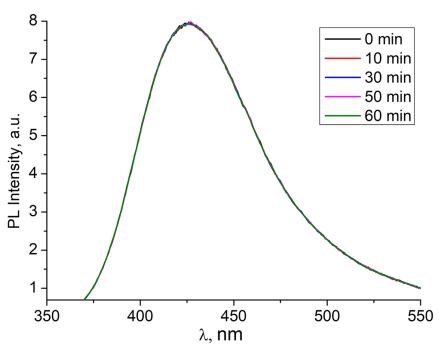

d)

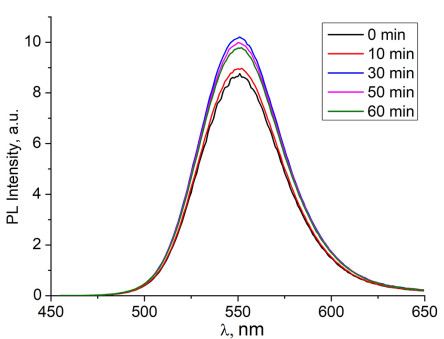

b)

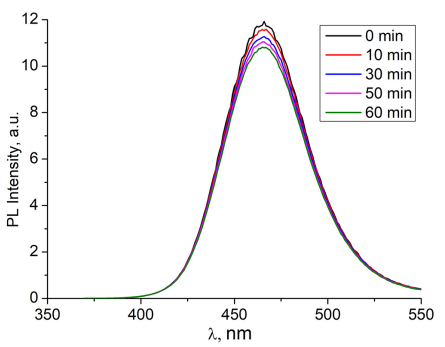

e)

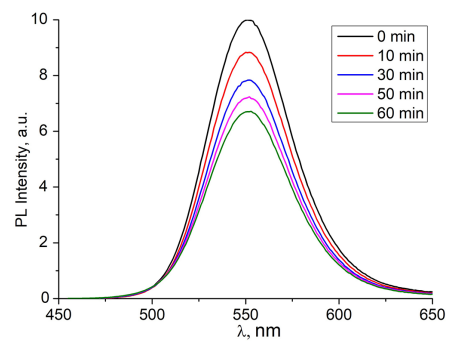

c)

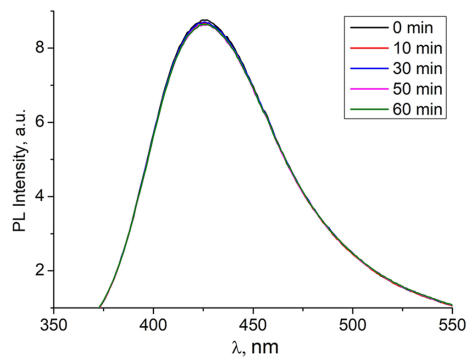

f)

Fig. 3. Evolution of luminescence spectra of samples a) CdTe control, b) CdTe visible irradiation, c) CdTe UV irradiation, d) CQD control, e) CQD visible irradiation, f) CQD UV irradiation 


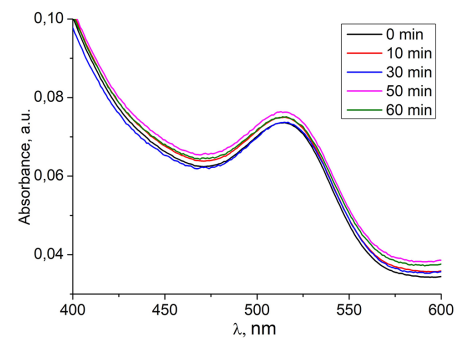

a)

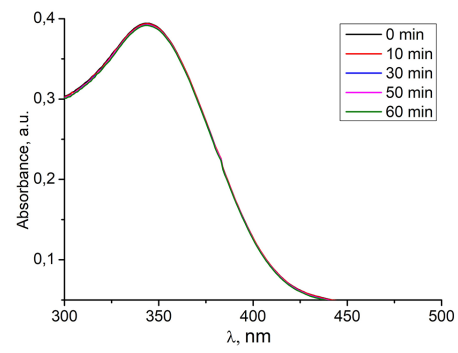

d)

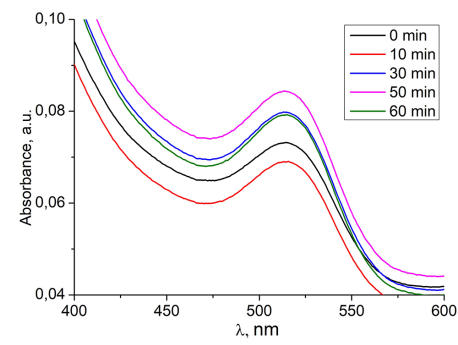

b)

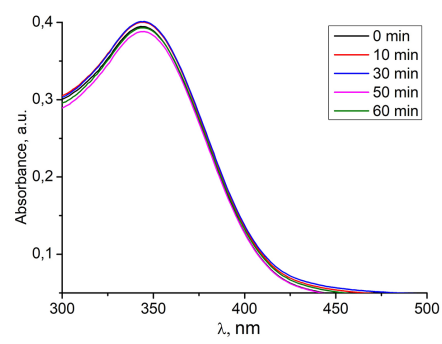

e)

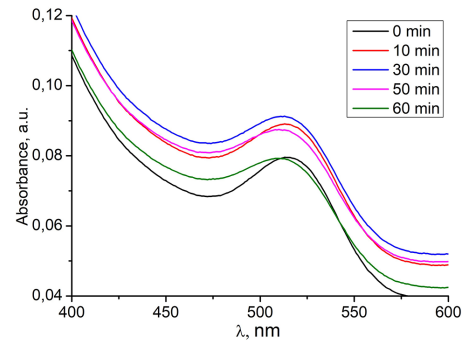

c)

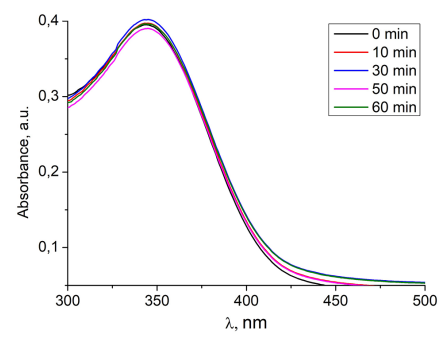

f)

Fig. 4. Evolution of absorption spectra of samples a) CdTe control, b) CdTe visible irradiation, c) CdTe UV irradiation, d) CQD control, e) CQD visible irradiation, f) CQD UV irradiation

leads to a significant decrease in both absorption and luminescence depending on the exposure time. In this case, exposure to radiation in the visible range leads to a significantly smaller change in these characteristics. In the case of graphene quantum dots, irradiation in both the visible and UV ranges has a smaller effect on the absorption and luminescence spectra.

For further analysis of the data obtained, the dependences of the magnitude of the maximum of the luminescence intensity and absorption were plotted, normalized to the magnitude of the maxima before the start of irradiation (Fig. 5).

As can be seen from Fig. 5, irradiation of the CdTe quantum dot solution with the UV range of the spectrum leads to a decrease in the maximum intensity of both absorption and luminescence. The initial increase in the maximum absorption intensity is associated with an increase in scattering by large agglomerates of particles formed during irradiation with ultraviolet light. The mechanism of the effect of UV radiation on quantum dots is considered in detail in the work [18]. At the same time, the maximum intensity for the control sample and the sample irradiated in the visible range practically does not change within the measurement error.

The behavior of graphene quantum dots is different. The luminescence intensity remains for all 3 samples within the measurement error. In the absorption spectra of graphene quantum dots, a decrease in intensity is observed upon irradiation with UV light. In contrast to CdTe quantum dots, no increase in the absorption intensity is observed at the initial stage, which suggests that these quantum dots do not form, at least at the initial stage, aggregates.

Fig. 6 shows the change in the luminescence and absorption wavelength maxima of quantum dots with the time of irradiation in different ranges.

Fig. 6a shows that the change in the maximum of the luminescence wavelength with the time of irradiation practically does not occur in all three CdTe samples. Note that the wavelength of the absorption maximum shifts to the region of shorter wavelengths, when irradiated with UV light, which is associated with a decrease in the size of individual particles, and the spectral 

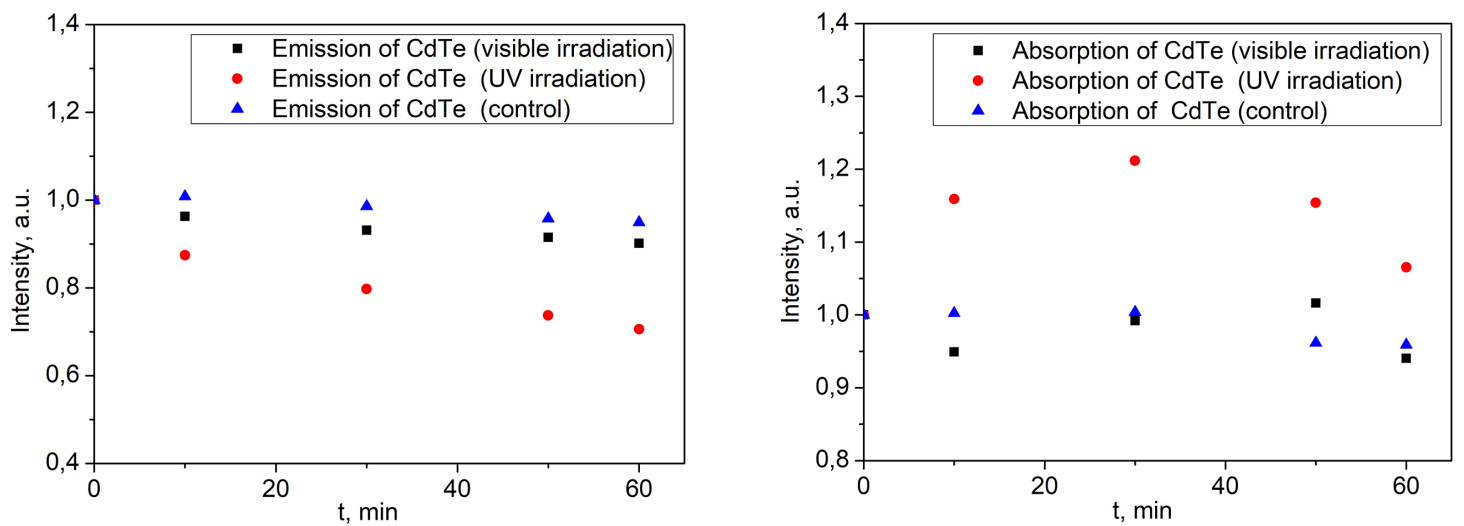

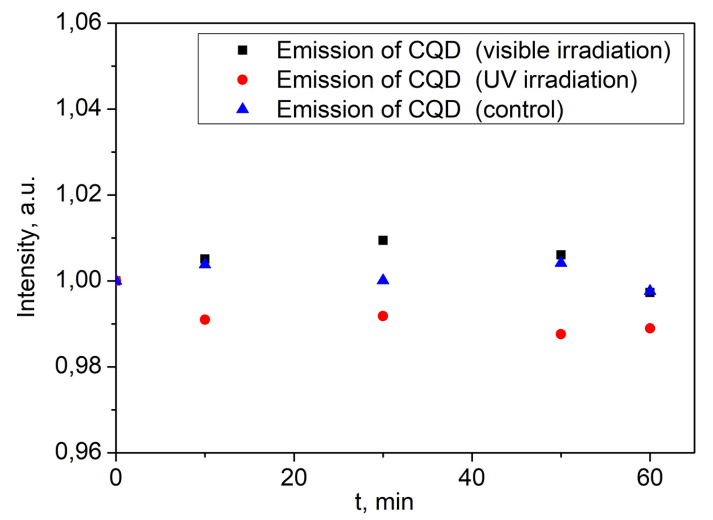

a)

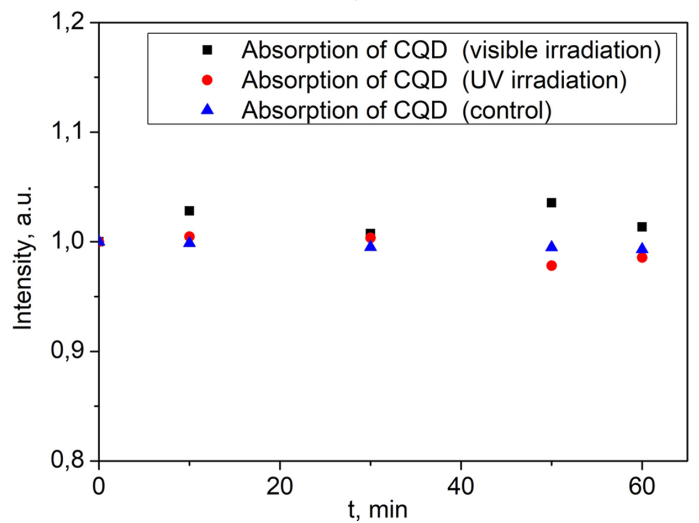

b)

Fig. 5. a) Normalized change in the maximum of the luminescence intensity from the exposure time, b) Normalized change in the maximum absorption intensity from the exposure time

position of the absorption maxima of samples numbered 1 and 2 (control and irradiated in the visible range) is practically match.

At the same time, the position of the absorption and luminescence maxima of graphene quantum dots practically does not undergo any changes, which suggests that the sizes of individual particles remain constant.

\section{Conclusion}

Colloidal graphene quantum dots and CdTe investigated in this work retain their optical and structural properties when exposed to radiation in the visible range, which is important for a number of their applications, for example, as solar cells. At the same time, their optical properties change when exposed to UV radiation. The latter allows them to be used as detectors that allow determining the dose of the radiation received. At the same time, the effect of UV radiation on CdTe quantum dots manifests itself in the form of a shift in the absorption maxima and an increase in optical density in the region of the first exciton transition due to particle aggregation and light scattering by large conglomerates, which leads to the need for additional processing of spectra. In the case of graphene quantum dots, the effect of UV radiation manifests itself in a decrease in the absorption maximum, which directly makes it possible to judge the received radiation dose. 

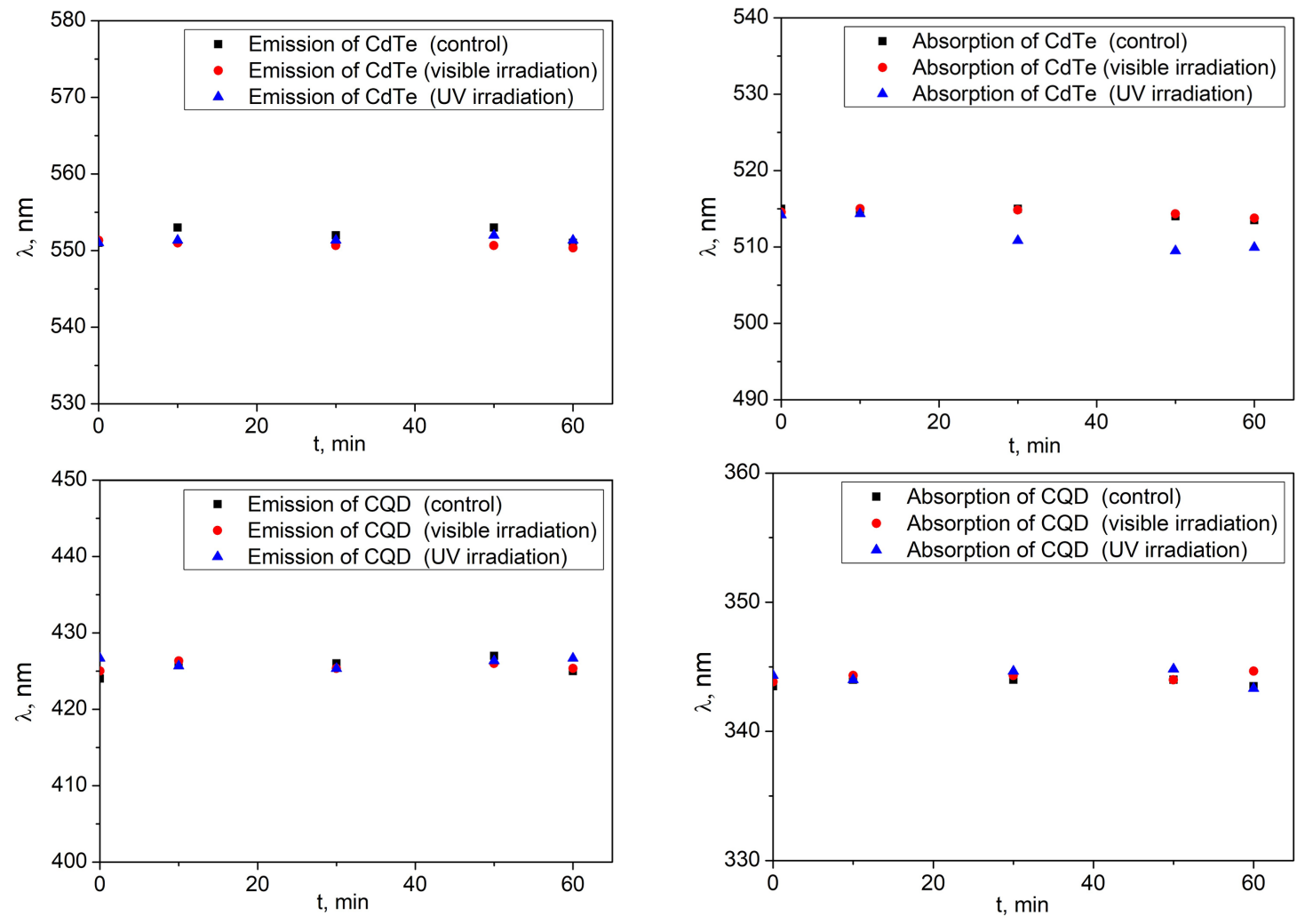

a)

b)

Fig. 6. a) Changes in the maximum of the luminescence wavelength from the time of irradiation, b) Changes in the maximum of the absorption wavelength from the time of irradiation

This research was supported by the Ministry of Science and Higher Education of the Russian Federation (Grant $M K-1355.2019 .2)$.

\section{References}

[1] E.D.Arama, V.F.Zhitar', T.D.Shemyakova, UV Sensors, Electronic Materials Processing, 42(2006), no. 5, 72-76 (in Russian).

[2] I.Artyukov, Ultraviolet Radiation Detectors, Photonics, 5(2008), 26-33 (in Russian).

[3] Y.Zheng, L.Cheng, M.Yuan, Z.Wang, L.Zhang, Y.Qin, T.Jing, An electrospun nanowirebased triboelectric nanogenerator and its application in a fully self-powered UV detector, Nanoscale, 6(2014), no. 14, 7842-7846. DOI: 10.1039/c4nr01934b

[4] D.Li, X.Sun, H.Song, Z.Li, Y.Chen, H.Jiang, G.Miao, Realization of a high-performance GaN UV detector by nanoplasmonic enhancement, Adv. Mater., 24(2012), no. 6, 845-849. DOI: $10.1002 /$ adma.201102585

[5] V.Adinolfi, O.Ouellette, M.I.Saidaminov, G.Walters, A.L.Abdelhady, O.M.Bakr, E.H.Sargent, Fast and Sensitive Solution-Processed Visible-Blind Perovskite UV Photodetectors, Adv. Mater., 28(2016), no. 33, 7264-7268. DOI: 10.1002/adma.201601196 
[6] A.Prakash, S.D.Nehate, K.B.Sundaram, Boron carbon nitride based metal-insulatormetal UV detectors for harsh environment applications, Optics Letters 41(2016), no. 18, 4249-4252. DOI: $10.1364 / \mathrm{ol} .41 .004249$

[7] M.R.Alenezi, A.S.Alshammari, T.H.Alzanki, P.Jarowski, S.J.Henley, S.R.P.Silva, ZnO Nanodisk Based UV Detectors with Printed Electrodes, Langmuir, 30(2014), no. 13, 3913-3921. DOI: $10.1021 / \mathrm{la} 500143 \mathrm{w}$

[8] M.R.Alenezi, S.J.Henley, S.R.P.Silva, On-chip Fabrication of High Performance Nanostructured ZnO UV Detectors, Sci. Rep, 5(2015), no. 1, 8516. DOI: 10.1038/srep08516

[9] M.Gong, Q.Liu, B.Cook, B.Kattel, T.Wang, W.-L.Chan, et.al., All-Printable ZnO Quantum Dots/Graphene van der Waals Heterostructures for Ultrasensitive Detection of Ultraviolet Light, ACS Nano, 11(2017), no. 4, 4114-4123. DOI: 10.1021/acsnano.7b00805

[10] S.Buhbut, S.Itzhakov, D.Oron, A.Zaban, Quantum Dot Antennas for Photoelectrochemical Solar Cells, Phys. Chem. Lett. J., 2(2011), no. 15, 1917-1924. DOI: 10.1021/jz200518q

[11] P.V.Kamat, Quantum Dot Solar Cells. The Next Big Thing in Photovoltaics, Phys. Chem. Lett. J., 4(2013), no. 6, 908-918. DOI: 10.1021/jz400052e

[12] K.-E.Kim, T.G.Kim, Y.-M.Sung, Fluorescent cholesterol sensing using enzyme-modified CdSe/ZnS quantum dots, Nanopart. Res. J., 14(2012), no. 10, 1-9.

DOI: $10.1007 / \mathrm{s} 11051-012-1179-8$

[13] N.Tessler, V.Medvedev, M.Kazes, S.Kan, U.Banin, Efficient near-infrared polymer nanocrystal light-emitting diodes, Science, 295(2002), no. 5559, 1506-1508.

DOI: $10.1126 /$ science. 1068153

[14] D.C.Oertel, M.G.Bawendi, A.C.Arango, V.Bulovic, Photodetectors based on treated CdSe quantum-dot films, Appl. Phys. Lett., 87(2005), no. 21, 213505. DOI: 10.1063/1.2136227

[15] I.A.Reznik, Y.A.Gromova, A.S.Zlatov, M.A.Baranov, A.O.Orlova, S.A.Moshkalev, V.G.Maslov, A.V.Baranov, A.V.Fedorov, Hybrid structures based on quantum dots and graphene nanobelts, Optics and Spectroscopy, 122(2017), no. 1, 114-119.

DOI: $10.1134 / \mathrm{s} 0030400 \times 17010258$

[16] O.V.Ovchinnikov, M.S.Smirnov, B.I.Shapiro, T.S.Shatskikh, A.N.Latyshev, P.T.H.Mien, V.Y.Khokhlov, Spectral manifestations of hybrid association of CdS colloidal quantum dots with methylene blue molecules, Optics and Spectroscopy, 115(2013), no. 3, 340-348.

DOI: $10.1134 / \mathrm{s} 0030400 x 1309018 \mathrm{x}$

[17] E.V.Ushakova, T.K.Kormilina, M.A.Burkova, S.A.Cherevkov, V.V.Zakharov, V.K.Turkov, A.V.Fedorov, A.V.Baranov, The influence of ligand type on self-organization and optical properties of cadmium selenide quantum dots, Optics and Spectroscopy, 122(2017), no. 1, 25-29. DOI: $10.1134 / \mathrm{s} 0030400 \times 17010301$

[18] A.S.Tsipotan, M.A.Gerasimova, A.S.Aleksandrovsky, S.M.Zharkov, V.V.Slabko, Effect of visible and UV irradiation on the aggregation stability of CdTe quantum dots, Nanopart. Res. J., 18(2016), no. 11, 324. DOI: 10.1007/s11051-016-3638-0 
[19] J.Ge, M.Lan, B.Zhou, W.Liu, L.Guo, H.Wang,et.al., A graphene quantum dot photodynamic therapy agent with high singlet oxygen generation, Nature Communications, 5(2014), no. 1, 4596. DOI: $10.1038 /$ ncomms5596

\title{
Фотостабильность коллоидных квантовых точек CdTe и графеновых квантовых точек при их облучении непрерывным излучением в видимом и УФ-диапазонах
}

Мелина А. Горюнова Алексей С. Ципотан Виталий В. Слабко Сибирский федеральный университет Красноярск, Российская Федерация

\begin{abstract}
Аннотация. В последнее десятилетие ультрафиолетовые детекторы привлекли значительное внимание из-за их широкого применения в гражданской и военной областях. В настоящей работе исследовано влияние излучения разных диапазонов (УФ- и видимого) на спектральные свойства квантовых точек CdTe и широкозонных графеновых KT. Полученные результаты могут быть использованы для создания интегрального детектора УФ-излучения на новых физических принципах.

Ключевые слова: детекторы УФ-излучения, квантовые точки, фотостабильность.
\end{abstract}

